\title{
5. DEEP CRUSTAL GEOTHERMAL MEASUREMENTS, HOLE 504B, DEEP SEA DRILLING PROJECT LEGS 69 AND 701
}

\author{
Keir Becker, Deep Sea Drilling Project, Scripps Institution of Oceanography, La Jolla, California, \\ Marcus G. Langseth, Lamont-Doherty Geological Observatory, Palisades, New York \\ and \\ Richard P. Von Herzen, Woods Hole Oceanographic Institution, Woods Hole, Massachusetts
}

\begin{abstract}
Seven temperature logs at Deep Sea Drilling Project Hole 504B reveal the geothermal state of the ocean crust to a depth of 836 meters. A linear temperature profile in the 275 meters of sediments fixes the heat flow at $196 \mathrm{~mW} / \mathrm{m}^{2}$, by dominantly conductive means. Two logs after Leg 69 drilling to 489 meters strongly indicate drawdown of bottom water into basement. Equilibrium temperatures measured immediately upon Leg 70 re-entry of the hole fix the flow rate at $90 \pm 5 \mathrm{~m} / \mathrm{hr}$, and indicate that the mass flux is directed into a thin zone from 330 to 360 meters sub-bottom. Extrapolation to equilibrium temperature of two logs after completion of all drilling shows that the gradient is linear from 489 to 837 meters, with a dominantly conductive heat flow of $188 \mathrm{~mW} / \mathrm{m}^{2}$, in excellent agreement with the value obtained in the sediments. In combination with the in situ pressure data of Zoback and Anderson (this volume), the temperature data indicate that the aquifer from 330 to 360 meters has anomalously high permeability of 0.2 darcy $\left(2 \times 10^{-13} \mathrm{~m}^{2}\right)$, and extends radially at least $1 \mathrm{~km}$ from the hole.
\end{abstract}

\section{INTRODUCTION}

The major scientific objective of the drilling programs on both Legs 69 and 70 was the assessment of the physical and chemical state of young oceanic crust. Toward this end, geothermal measurements were especially important in monitoring the processes by which the crust cools at various sites. At the Costa Rica Rift, the combination of the site-survey surface-heat-flow data (Langseth et al., this volume) and the several deep temperature logs measured on Legs 69 and 70 provides a unique, two-dimensional revelation of the modes of heat and mass transfer within well-sedimented young ocean crust.

Site 504 is located on $6.2-\mathrm{m}$.y-old crust, with 275 meters of sediment cover. Langseth et al., (this volume) found the surface heat flow here uniformly close to that predicted by a cooling half-space model; thus, they concluded that the 250 to 275 meter sediment layer was sufficiently thick to prevent hydrothermal circulation between basement and bottom water. Their data also indicate that, closer to the spreading axis, such hydrothermal exchange occurs vigorously, as it does at most of the world's spreading centers; thus, the crust at Site 504 may be considered to have been, before Leg 69 drilling, close to full recovery from a probably earlier hydrothermal history.

Drilling through the sediment seal disturbed this state, and should be viewed as a large-scale experiment in which both the prior equilibrium state and the newly induced disturbances are of interest. In this situation, bore-hole temperature measurements are especially pertinent, because from them can be deduced both the past

\footnotetext{
${ }^{1}$ Cann, J. R., Langseth, M. G., Honnorez, J., Von Herzen, R. P., White, S. M., et al, Init. Repts. DSDP, 69: Washington (U.S. Govt. Printing Office).
}

undisturbed geothermal state and the subsequent modes of fluid and heat transfer in the hole and surrounding crust. In combination with other experiments, particularly the packer tests of Zoback and Anderson (this volume), the set of temperature logs at Hole 504B offers an exciting glimpse at the answers to several important questions about cooling processes in the young oceanic crust:

Is the sediment cover really the seal that stops hydrothermal circulation, as surface-heat-flow data suggest? If so, by what means is heat transfer accomplished within the basalt beneath the sediments? How representative of these deep heat-transfer processes is the sea-floor heat flow, particularly when it is close to plate-model predictions, as at Site 504? What is the physical state of the crust beneath the sediment seal, especially regarding temperature, fluid pressure, and basement permeability to fluid flow?

\section{METHODS}

Bore-hole temperatures at Hole 504B were logged seven times during Legs 69 and 70. During Leg 69, undisturbed sediment temperatures were measured at four depths at Hole 504C, which was offset 60 meters from 504B. Two continuous temperature logs were run in 504B after it had been drilled to 489 meters. The four logs run during Leg 70 include one about 40 days after the Glomar Challenger left the site at the end of Leg 69, before any further disturbance to the hole; one after an intermediate phase of drilling; and two after completion of drilling to 836 meters. Thus, the hole was at various stages of thermal disequilibrium during the measurements. Two separate devices were used to monitor temperature, the DSDP down-hole temperature probe Tokyo probe (T-probe), and the Gearhart-Owen high-resolution temperature-logging tool (HRT). Table 1 summarizes the equipment used in the state of the hole during each of the measurements. Before considering the measurement data, we briefly discuss the procedures used and the relative accuracies of the data.

The DSDP T-probe is described in detail by Yokota et al. (1980). The sensor housing has been modified subsequently for greater strength and lower time constant. This device records 128 resistance values of a single thermistor at 1 - or 2 -minute intervals. It has a precision of 10 
Table 1. Summary of bore-hole temperature logging at Hole 504B.

\begin{tabular}{|c|c|c|c|c|}
\hline Leg & Date & Total & $\begin{array}{c}\text { Hole Depth } \\
\text { (sub-bottom m) }\end{array}$ & Hole Condition \\
\hline \multirow[t]{3}{*}{69} & 14 October & T-probe & to 220 & $\begin{array}{l}504 \mathrm{C} \text { sediment temperature at } \\
\text { four depths } 60 \mathrm{~m} \text { from 504B }\end{array}$ \\
\hline & 22 October & HRT & 489 & $\begin{array}{l}34 \mathrm{hr} \text { after drilling circulation } \\
\text { ceased }\end{array}$ \\
\hline & 24 October & HRT & 489 & $\begin{array}{l}70 \mathrm{hr} \text { after drilling circulation } \\
\text { ceased }\end{array}$ \\
\hline \multirow[t]{4}{*}{70} & 3 December & T-probe & 489 & $\begin{array}{l}43 \text { days after Leg } 69 \text { drilling } \\
\text { circulation ceased }\end{array}$ \\
\hline & 8 December & T-probe & 656 & $\begin{array}{l}30 \mathrm{hr} \text { after drilling circulation } \\
\text { ceased }\end{array}$ \\
\hline & 14 December & HRT & 836 & $\begin{array}{l}40 \mathrm{hr} \text { after drilling circulation } \\
\text { ceased }\end{array}$ \\
\hline & 16 Decembèr & HRT & 836 & $\begin{array}{l}75 \mathrm{hr} \text { after drilling circulation } \\
\text { ceased }\end{array}$ \\
\hline
\end{tabular}

ohms, providing nominal temperature resolution of 0.01 to $0.02^{\circ} \mathrm{C}$. The thermistor is encased in a 1.25 -cm-diameter steel tip, with a time constant of about 2 to 3 minutes, depending on the sediment or water diffusivity. As used at Site 504, the probe latches into the bottom-hole assembly, so that it protrudes about 1 meter ahead of the core bit. It then can be pushed into soft sediments undisturbed by drilling, for sediment temperature measurements (Erickson et al., 1975), as at Hole 504C. Alternatively, it can be lowered in several steps through the drilled hole, to obtain discrete readings of bore-hole water temperature at depth, as during two Leg 70 measurements. Depth control is accurately determined from total drill string length below the ship.

The HRT logging tool also uses a calibrated resistance element, which is encased in a probe smaller than the DSDP T-probe, so its time constant ( $\leqslant 1 \mathrm{~min}$ ) is considerably lower. The HRT tool is lowered slowly on a logging cable, and the water temperature is continuously logged. The delay in the response of the HRT probe introduces a consistent error in determining bore-hole temperatures: they are under-estimated by the logged temperature during instrument lowering, and overestimated while hoisting. Because the magnitude of this effect is small $\left(\simeq 0.5^{\circ} \mathrm{C}\right)$ at slow winch speeds, we have not corrected any of our logged temperature data. All the data shown here were obtained on out-going logging runs. Depth control is provided by the logging winch counter, which can be corrected by checking bottom-hole depth readings.

The thermistor used in the DSDP T-probe had been calibrated over a 0 to $100^{\circ} \mathrm{C}$ temperature span; the high range of measured temperatures-about $120^{\circ} \mathrm{C}$-required extrapolation of this calibration. The absolute accuracy of the T-probe temperature readings is estimated at about $0.01^{\circ} \mathrm{C}$. On the other hand, the calibration of the HRT tool is not well known. Based on comparison of HRT readings at the mudline with the known bottom-water temperature, and on comparison with DSDP tool results, we estimate the error in HRT readings at about $\pm 1^{\circ} \mathrm{C}$. In light of both the high heat flow at this hole and the vigorous advective processes we observe in the hole, the combined temperature and depth errors for both instruments are relatively insignificant, propagating as uncertainties of about $5 \%$ in our results.

\section{DATA INTERPRETATION}

As noted above, all the temperature measurements in Hole 504B were taken under some condition of thermal disequilibrium in the hole, because of drilling. On Leg 69 , it became apparent, when comparing the conductive sediment-temperature profile in Hole $504 \mathrm{C}$ to the first two logs in 504B, that an additional transient thermal process must be occurring in 504B (Fig. 1). From the shape of the two Leg 69 logs, it was deduced that ocean bottom water must be flowing down the hole at several tens of meters per hour into a permeable formation at about 350 meters sub-bottom; however, because it is difficult to separate the thermal transient due to the suddenly active flow down the hole from that due to drilling

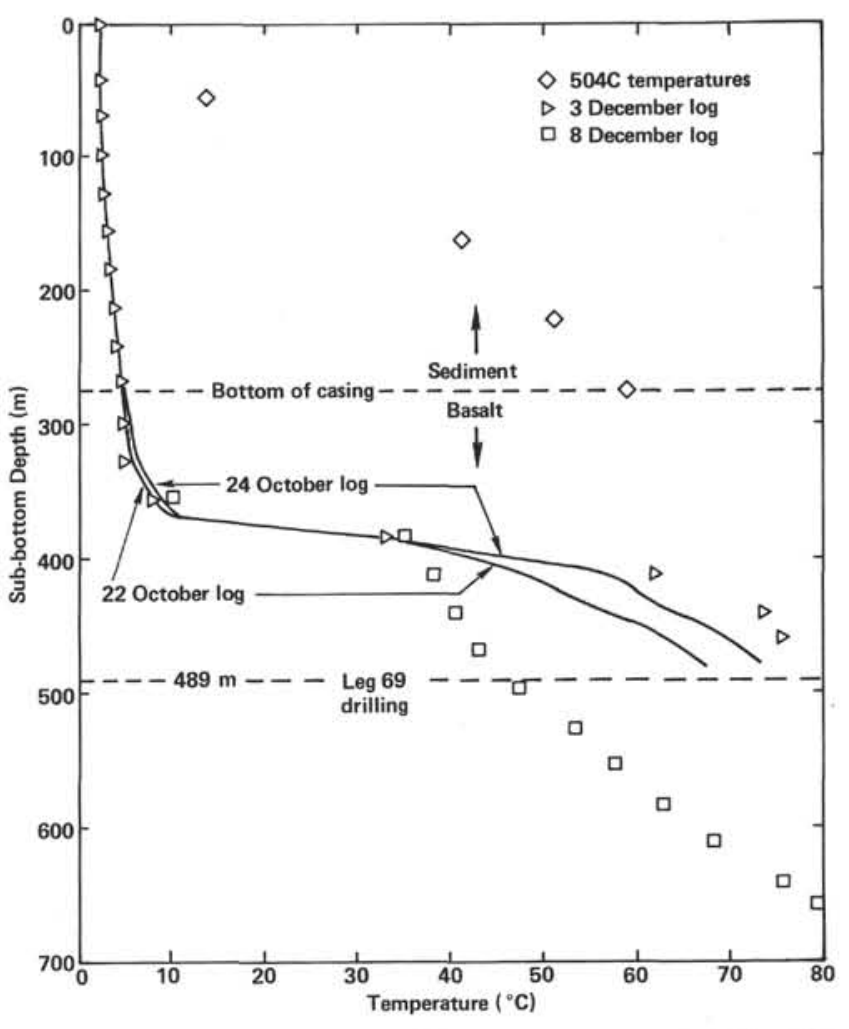

Figure 1. Temperatures measured in the upper part of Hole 504B through the first phase of Leg 70 drilling. Instrumentation and hole conditions are summarized in Table 1.

disturbance, the two Leg 69 logs in 504B are difficult to interpret without further constraints.

The first activity on Leg 70's re-entry of Hole 504B was a temperature log in the upper 489 meters, which represents the best assessment of thermal conditions undisturbed by drilling. This log was taken 43 days after the end of the 6 to 8 days of Leg 69 drilling disturbance of the hole, a time long enough for drilling disturbance to dissipate largely; i.e., the hole temperatures should have recovered to within 1 or $2 \%$ of the undisturbed profile (Bullard, 1947; Jaeger, 1961). This log, and a subsequent $\log$ on 8 December, after the hole had been drilled to 656 meters, showed that there still was a strong flow down the hole into a permeable zone at about 350 meters (Fig. 1). The last two logs, taken after the hole was drilled to 836 meters, allowed an assessment of the equilibrium thermal conditions in the deeper part of the hole, which seemed to be unaffected by the advective processes in the upper 350 meters.

In the following section, we assess the geothermal data in terms of both an accurate determination of the heat flow near Site 504, and a reliable estimate of the time-averaged flow rate down the hole. The equilibrium geothermal heat flow is a boundary and initial condition for the down-hole flow problem; therefore, we start with several determinations of the conductive heat flow in the area: sea-floor measurements and sediment-temperature measurements at Sites 504C and 501 (Langseth et al., this volume), and the final two temperature logs in Hole 504B. These give quite consistent results. Two 
methods are used to estimate the down-hole flow rate based on the near-equilibrium 3 December log: a quasisteady-state approximation, and a fully transient analytical solution.

\section{SEDIMENT GEOTHERMAL MEASUREMENTS AT SITE 504}

A detailed discussion of site-survey surface-heat-flow measurements and sediment temperatures at Holes 501, $504 \mathrm{~A}$, and $504 \mathrm{C}$ is given by Langseth et al. (this volume). Within about $10 \mathrm{~km}$ from Hole 504B, surface heat flows are very uniform at about $200 \mathrm{~mW} / \mathrm{m}^{2}$, very close to the value expected for $6.2-\mathrm{m}$.y.-old ocean crust. Sediment temperatures measured at Holes 501, 504A, and $504 \mathrm{C}$ are in good agreement with this heat-flow value. At 504C, offset about 60 meters from 504B, sediment temperatures are reasonably linear with integrated thermal resistance, indicating a dominantly conductive heat flow of $196 \mathrm{~mW} / \mathrm{m}^{2}$ (4.68 HFU). A major implication of these measurements is that the 275 meters of sediment cover forms an impenetrable barrier to fluid exchange between the basement and bottom water. Thus, before 504B was drilled, a conductive temperature gradient must have existed down to the sediment/basement contact. Extrapolation of the conductive-heat-flow temperature profile to 275 meters yields an equilibrium temperature of 58 to $59^{\circ} \mathrm{C}$ at this contact.

\section{DEEP BORE-HOLE TEMPERATURES}

The two HRT temperature logs run at the end of Leg 70 were taken after cessation of drilling and flushing of the hole; thus, they provide a good data set for application of the theories of the return of a bore-hole to equilibrium formation temperature. Several theories are available, all based on solutions of the heat-conduction equation for a solid bounded internally by an infinite circular cylinder. Various boundary conditions at the internal cylinder lead to the various solutions. Hyndman et al. $(1976,1977)$ give a detailed comparison of these solutions (as well as a detailed discussion of borehole conditions relevant to these theories); here we briefly discuss the three best possibilities:

Bullard (1947) represented the drilling process with an infinite line source of heat, and derived an approximate expression for the temperature in the bore hole after drilling is stopped. This theory ignores the thermal properties of the bore-hole fluid. Cooper and Jones (1959), after Bullard (1954), successfully use the theory for the decay of temperature after the instantaneous emplacement of cold water in the hole, to extrapolate bottom-hole temperatures to equilibrium value; however, this theory is approximately valid only for very short disturbance times, i.e., in the deepest parts of a bore hole. Hyndman et al. $(1976,1977)$ prefer the solution of Jaeger $(1956,1961)$ for the temperature decay after the hole is held at a constant temperature for a time corresponding to the drilling-disturbance time. This well may be the best approximation for a relatively shallow, low-heat-flow hole, where the drilling fluid temperature may be taken as relatively constant with depth, and close to the bottom-water temperature; however, for the deep, high-heat-flow Hole 504B, the assumption of constant drill-fluid temperature at depth during the drilling process probably breaks down. For this reason, and because there were several periods of drilling, with intervening hiatuses, we originally applied the theory of Bullard (1947) to our measurements; the results presented here were obtained with this method. Lachenbruch and Brewer (1959) obtained excellent results with this theory, and give a complete discussion of the possible errors involved.

Jaeger's (1956a,b, 1961) constant-temperature theory can be modified to accommodate both a depth variation of temperature and discontinuous drilling (Burch and Langseth, in press). This method is probably more accurate than Bullard's (1947), but it requires careful monitoring of circulation rates. Since the total circulation rate in Hole 504B was some undetermined combination of forced pumping and naturally induced draw-down, application of this method could be subject to considerable error. Preliminary results of the method are in reasonable agreement with the following application of Bullard's (1947) treatment.

The temperature of a bore hole and the surrounding rock are disturbed by the frictional heating of drilling, and the more important advection of heat by circulating drilling fluids. In Bullard's (1947) theory (see also Jaeger, 1965, p. 17), this disturbance is represented by a source $Q(z)$, constant with depth, with cylindrical symmetry about the table, which yields an analytical expression for the temperature near the hole:

$$
T(z, t)=\frac{-Q(z)}{4 \pi K} \operatorname{Ei}\left(-r^{2} / 4 k t\right)
$$

where

$$
\begin{aligned}
K & =\text { thermal conductivity of crust } \\
k & =\text { thermal diffusivity of crust } \\
r & =\text { radial distance from hole }
\end{aligned}
$$

and

$$
-\operatorname{Ei}(-x)=\int_{x}^{\infty} \frac{\mathrm{e}^{-u}}{u} \mathrm{~d} u
$$

The cessation of drilling at time $t_{1}$ is modeled by addition of a negative source starting at $t_{1}$. For small values of $r$, i.e., in the bore hole, the asymptotic approximation for the exponential integral is used:

$$
\underset{z \rightarrow 0}{\operatorname{Ei}(-z) \sim \log z+0.577}
$$

This yields, for the transient temperature disturbance after the cessation of drilling,

$$
T=\frac{Q}{4 \pi K} \log \left(1+t_{D} / t\right)
$$


where

$$
\begin{aligned}
t_{D} & =\text { time spent drilling } \\
t & =\text { time after drilling }
\end{aligned}
$$

Then, if temperatures are measured at least two times after drilling for a time $t_{D}$, they can be extrapolated to $t=\infty$, when the disturbance temperature dies out, and the equilibrium temperature is reached.

The application of this theory to a complex drilling history with several pauses in drilling, as occurred at Hole 504B, is straightforward, under the assumption that a time-varying source strength can be adequately represented by a constant averaged value. This is difficult to justify in general; in this case, it apparently is upheld by the excellent continuity of results from separate sections of the hole which were subject to different drilling histories. Given this assumption, the temperature disturbances can be superposed, yielding, for the total disturbance $T_{\mathrm{T}}$,

$$
T_{\mathrm{T}}=\frac{Q}{4 \pi K} \sum^{i} \log \left(1+t_{\mathrm{D} i} / t_{i}\right)
$$

where the $i$ 's refer to the separate episodes of drilling. Equilibrium basement temperatures for Hole 504B were obtained by extrapolation to $t=\infty$ with this relationship. For the deeper part of the hole, three different phases of Leg 70 drilling were applied to (1); for the shallower section, it was assumed that the Leg 69 drilling disturbance had totally dissipated, so that the total Leg 70 drilling history was applied to (1) for the section drilled by Leg 69 .

The results of this extrapolation are plotted on Figure 2 , along with the near-equilibrium 3 December log, and the sediment-temperature measurements at Hole 504C. Also shown is the best-fit temperature gradient through the extrapolated temperatures, based on linear regression on the points in only the Leg 70 portion of the hole, neglecting the two points which deviate from the trend at the bottom of the hole. (These two low bottom-hole temperatures are discussed at the end of this section.) Because the absolute accuracy of the log temperature values is estimated at $\pm 1^{\circ} \mathrm{C}$, but the relative accuracy is much better, the propagated error in the extrapolation is probably $\pm 1^{\circ} \mathrm{C}$.

The linear regression of the extrapolated temperatures yields a basement thermal gradient of $0.114^{\circ} \mathrm{C} / \mathrm{m}$, with a standard error of fit of temperature to depth equal to $0.44^{\circ} \mathrm{C}$. Using the average basalt thermalconductivity data of Karato (this volume), $1.65 \pm 0.10$ $\mathrm{W} / \mathrm{m} \cdot \mathrm{K}$, and Karato et al. (this volume), $1.68 \pm 0.07$ $\mathrm{W} / \mathrm{m} \cdot \mathrm{K}$, we determine the heat flow between 400 and 800 meters sub-bottom to be $188 \pm 11 \mathrm{~mW} / \mathrm{m}^{2}(4.48 \pm$ $0.27 \mathrm{HFU})$. This is in excellent agreement with the average surface heat flow of $200 \mathrm{~mW} / \mathrm{m}^{2}$, and the Hole $504 \mathrm{C}$ sediment heat flow of $196 \mathrm{~mW} / \mathrm{m}^{2}$ obtained by Langseth et al. (this volume).

Because the thermal conductivity data were obtained from solid and usually unfractured basalt samples, they

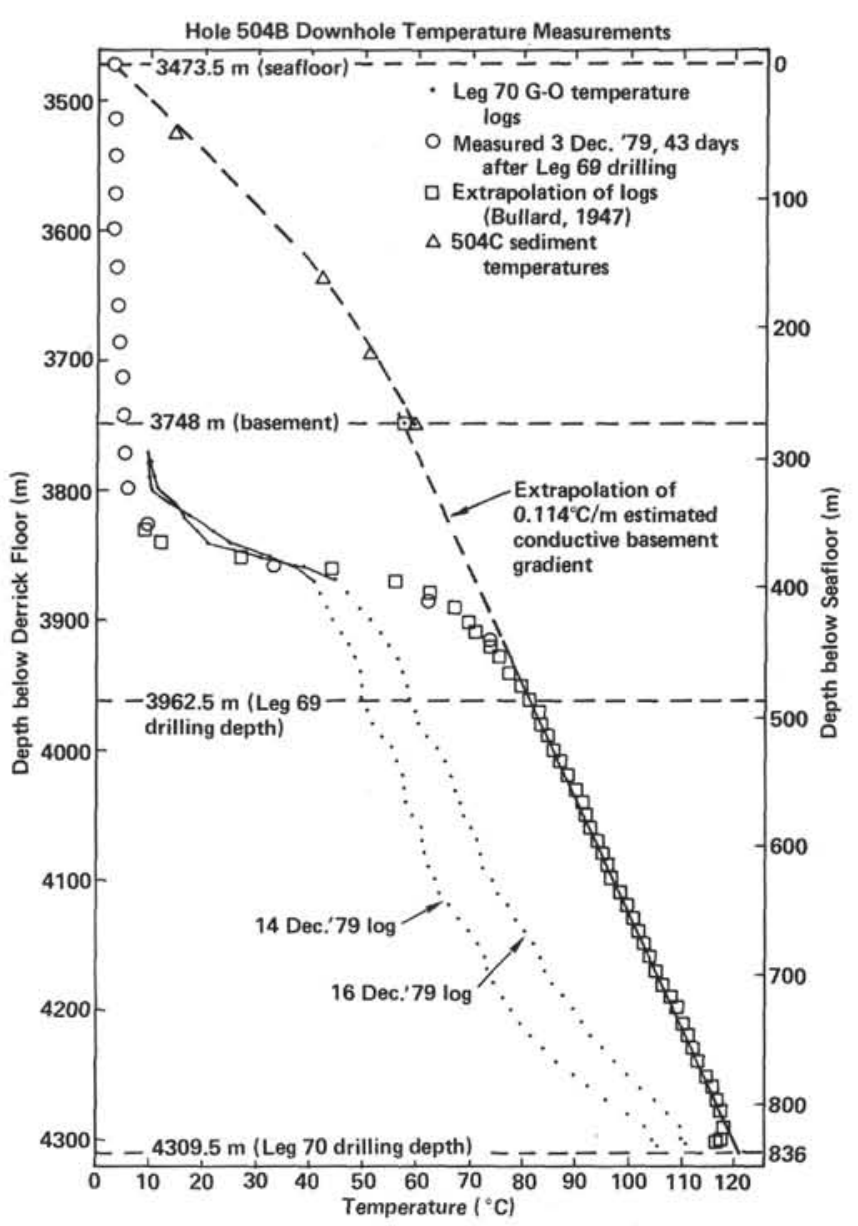

Figure 2. Bore-hole temperatures measured before and after Leg 70 drilling and equilibrium crustal temperatures obtained by extrapolation of last two logs. Note good agreement of sediment/basement-contact temperature obtained by extrapolation of independent measurements from above and below.

may not be representative of the bulk conductivity of the porous basement. Our basement heat flow estimate should then be taken as an upper bound; however, judging from the high Layer $2 \mathrm{~A}$ compressional-wave velocities near Hole 504B $(4.3-5.1 \mathrm{~km} / \mathrm{s}$; Langseth et al., this volume), and from the basement-pore-water underpressures (see Zoback and Anderson, this volume), the bulk porosity of the basement here must be fairly low. The basalt rock conductivity should dominate the basement section conductivity, which is probably within 5 to $10 \%$ of the measured basalt values (see Hyndman and Drury, 1976); therefore, we have not attempted to correct the basement heat flow to in situ conditions.

The striking linearity of the extrapolated equilibrium temperatures, and the excellent agreement of this gradient with the results of the heat-flow measurement at Hole 504C, have several important implications:

1) The good relative accuracy of the HRT temperature tool apparently is confirmed.

2) The simplified, time-average theory of Bullard (1947), used to treat the data, is shown to be adequate in this case. 
3) It appears that, prior to drilling Hole 504B, the thermal regime of the ocean crust here was purely conductive; moreover, this has now been shown to hold a depth of nearly $1 \mathrm{~km}$.

4) As deduced from earlier logs, none of the bottom water flowing down the hole can be detected flowing past a depth of about 400 meters.

An attempt was made to apply the theory of Cooper and Jones (1959) to the bottom-hole temperatures which do not fit the Bullard (1947) extrapolation well; however, the data could not be fit satisfactorily by this method, because the time delays for the two logs are somewhat too large for the method to work well. At 40 and 75 hours, the theoretical extrapolations depend on the very small difference of two small quantities, the determination of which depends on precise specification of the thermal properties of the bore-hole fluid and the surrounding medium. We suspect that the relatively lowtemperatures at the bottom of the hole may be due to slow settling of cold debris from above.

\section{CALCULATION OF RATE OF WATER FLOW DOWN HOLE 504B}

With the accurate determination of the equilibrium conductive heat flux at 504B, we have established an important initial and boundary condition that governs the transient bore-hole temperature after the establishment of fluid flow along the bore hole. Our primary data set for the estimation of a time-averaged flow rate is the Leg 70 temperature log of 3 December, which we again take to be at equilibrium with respect to Leg 69 drilling disturbances. We confine our attention to the 275-meter cased section of the hole, where the flow rate must of course remain constant with depth. We consider only constant material parameters, averaged over the sediment column. Parameters used in the following calculations are defined and evaluated in Table 2 . We obtain two consistent estimates of the flow rate, the first by applying the results of Jaeger (1942) for radial conduction about an isothermal circular cylinder, and the second, after Lesem et al., (1957), by numerical integration of the exact solution for a radial-conduction problem with the appropriate boundary condition. In both cases, we

Table 2. Definition of variables and values of parameters used in flow rate calculation. ${ }^{\mathrm{a}}$

\begin{tabular}{|c|c|c|}
\hline Variable/Parameter & Value & Source \\
\hline $\begin{array}{l}K_{\mathrm{e}} \text {, thermal conductivity } \\
x \text {, thermal diffusivity }\end{array}$ & $\begin{array}{l}0.95 \mathrm{~W} / \mathrm{m}^{\circ} \mathrm{C} \\
2.7910^{-7} \mathrm{~m}^{2} / \mathrm{s}\end{array}$ & $\begin{array}{l}\text { Shipboard measurements } \\
K_{\mathrm{e}} /\left(\mathrm{e}^{c}\right)_{\mathrm{e}} \text {; eq. (5) of Von Herzen } \\
\text { and Maxwell (1959) }\end{array}$ \\
\hline $\begin{array}{l}\text { (ec), volumetric heat capacity } \\
\text { of water }\end{array}$ & $4.18710^{6} \mathrm{~J} / \mathrm{m}^{3}{ }^{\circ} \mathrm{C}$ & \\
\hline $\begin{array}{l}a \text {, hole radius } \\
T(z, a) \text {, temperature of water in } \\
\text { the bore hole }\end{array}$ & $0.15 \mathrm{~m}$ & \\
\hline $\begin{array}{l}T(z, \infty) \text {, undisturbed temperature } \\
\text { far from the bore hole }\end{array}$ & & \\
\hline$T_{b}$ temperature at bottom of casing & $2.4^{\circ} \mathrm{C}$ & Dec. $3 \log$ \\
\hline $\begin{array}{l}\text { g, geothermal gradient } \\
\ell \text {, length of casing in hole }\end{array}$ & $\begin{array}{l}0.205^{\circ} \mathrm{C} / \mathrm{m} \\
275 \mathrm{~m}\end{array}$ & Measured at Hole $504 \mathrm{C}$ on Leg 69 \\
\hline$t$, time since start of flow & $50 \pm 1$ day & $\begin{array}{l}\text { Time from drilling through } 350 \mathrm{~m} \\
\text { to Dec. } 3 \text { temperature log }\end{array}$ \\
\hline$\tau$, dimensionless time $=x t / a^{2}$ & 53.6 & \\
\hline$I(\tau)=\int_{0}^{\infty} \frac{e^{-\tau u^{2}} \mathrm{~d} u}{u\left[J_{0}^{2}(u)+Y_{0}^{2}(u)\right]}=$ & 0.946 & Jaeger and Clarke (1942) \\
\hline
\end{tabular}

\footnotetext{
a Subscripts: $e=$ earth, $w=$ water in bore hole.
}

assume that the bore-hole fluid is well mixed, so fluid temperatures do not vary radially. This assumption is later justified by the magnitude of the flow rate we obtain.

\section{A FLOW RATE ESTIMATE BASED ON A STEADY-STATE MODEL}

A comparison of Leg 69 temperature logs at Hole 504B with logs from Leg 70 indicates that temperatures in the upper 350 meters of the hole remain fairly constant with time. This implies that the thermal regime in the hole is close to steady state, and that we can apply a simple heat-exchanger model to estimate the flow rate (e.g., Jaeger, 1942, 1961). In this model, within each small interval of depth in the hole, the net heat flux due to the flow of water, $v$, is balanced by the radial flow of heat through the hole walls, $\mathrm{f}(z, a)$ (Fig. 3).

Following Jaeger (1961), the radial heat flow through the hole wall at $r=a$ is estimated by

$$
\mathrm{f}(z, a)=\frac{4 K_{\mathrm{e}} \Delta T(z)}{\pi^{2} a} I(\tau),
$$

where $\Delta T(z)=T(z, \infty)-T(z, a)$ (Table 2). For the sediments at Site 504, the temperature increases nearly uniformly with depth. Thus, $T(z, \infty)=g z$.

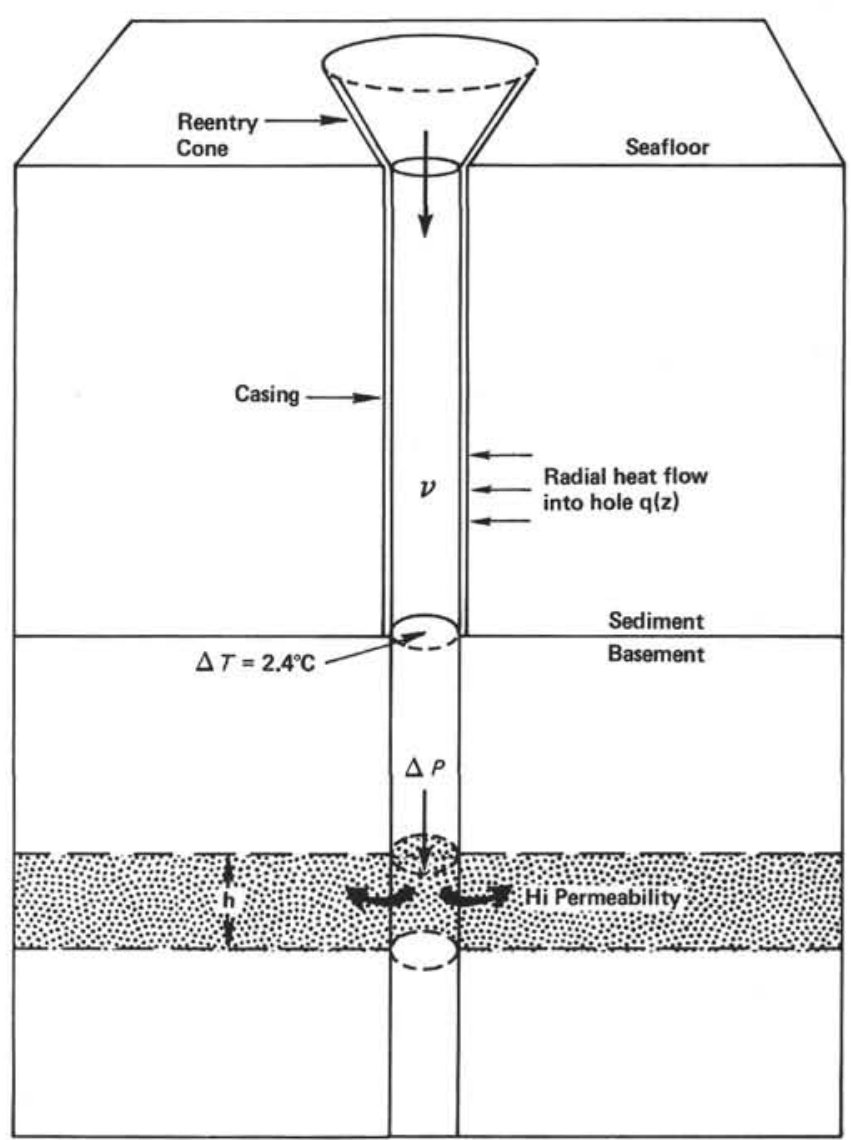

Figure 3. Sketch of hole as modeled to determine steady-state estimate of flow-rate, and for infinite-reservoir model of permeable formation in basement. 
The flux balance into a small depth element, $d z$, of the bore hole can, therefore, be written:

$$
\pi a^{2} v(\varrho c)_{\mathrm{w}} \frac{\mathrm{d} T(z, a)}{\mathrm{d} z}+2 \pi a \mathrm{f}(z, a)=0
$$

Using equation (2), this differential equation can be written as

$$
\frac{\mathrm{dT}(z, a)}{\mathrm{d} z}+\gamma(T(z, a)-g z)=0
$$

where $\gamma=8 K_{\mathrm{e}} I(\tau) / \pi^{2} a^{2} v(\varrho c)_{\mathrm{w}}$ is

For the condition that $T(0, a)=0$, the solution to (4)

$$
T(z, a)=g z+\frac{\mathrm{g}}{\gamma}\left[\mathrm{e}^{-\gamma z}-1\right]
$$

We can determine the value of $v$ from knowledge of the temperature at any depth other than $z=0$ in the hole. Thus, if $T_{\ell}=T(\ell, a)$, which is known from the $\operatorname{logs}$

$$
T_{\ell}=g \ell+\frac{\mathrm{g}}{\gamma}\left[\mathrm{e}^{-\gamma \ell}-1\right]
$$

or,

$$
\ln \left[\left(T_{\ell}-g \ell\right) \frac{\gamma}{\mathrm{g}}+1\right]+\gamma^{\ell}=0
$$

The non-zero root of (6) is the value of $\gamma$ that yields the observed $\mathrm{T}_{\ell}$, and from $\gamma$ the value of $v$ can be determined readily. For the parameters given in Table 2, $v=2.45 \mathrm{~cm} / \mathrm{s}$, or $88 \mathrm{~m} / \mathrm{hr}$.

An equivalent integral formulation of the problem can also be used to find an explicit expression for $v$. We set the total heat advected through the bottom of the casing equal to the total heat conducted through the walls of the hole; i.e.,

$$
\pi a^{2} \mathrm{v}(\varrho c)_{\mathrm{w}} \quad \int_{0}^{\ell} \frac{\mathrm{d} T(z, a)}{\mathrm{d} z} \mathrm{~d} z=2 \pi a \int_{0}^{\ell} \mathrm{f}(z, a) \mathrm{d} z
$$

Substitution of (2) and integration leads to

$$
v=\frac{4 \ell K_{\mathrm{e}} I(\tau)}{\pi 2 a 2(\varrho c)_{\mathrm{w}}} \cdot\left[\frac{g \ell-T_{\ell}}{T_{\ell}}\right]
$$

For the parameters in Table 2, this also yields $v=88$ $\mathrm{m} / \mathrm{hr}$.

\section{A FLOW-RATE ESTIMATE BASED ON A MODEL THAT INCLUDES TRANSIENT HEAT FLOW IN THE BORE HOLE}

To obtain an independent estimate of the time-averaged flow rate, we solved a more complete, fully tran- sient formulation of the problem in a semi-infinite geometry with prescribed initial values. We followed the development of Lesem et al. (1957), who solved a similar problem for the temperature distribution in a producing gas well. These authors solved a dimensionless version of the problem by a two-dimensional Laplace Transform, and presented similarity graphs of the solution, which are, unfortunately, inappropriate for water flow in a bore hole. The development is given in the Appendix in a dimensional form. The bore-hole temperature is obtained by numerical integration of a complicated function; there is no analytic method of inverting for the flow rate. However, with a reliable estimate of time since the flow started, the time-averaged flow rate can be obtained with reasonable precision, by fitting measured temperatures to the numerical temperaturedepth profiles.

Temperatures measured on 3 December in the cased section of Hole 504B and theoretical profiles obtained from equation (A19) (Appendix) are plotted in Figures 4A and 4B for different values of a constant down-hole flow rate. Aside from some misfit in the upper part of the hole, where temperatures only poorly resolve the flow rate, the measured bore-hole temperatures fit the theoretical profile for $90 \mathrm{~m} / \mathrm{hr}$ very well. This value agrees reasonably well with our previous estimate, and seems to justify the approximations made in the first calculation.

Figure 5 shows the transient development of the theoretical temperature for a constant $90 \mathrm{~m} / \mathrm{hr}$ flow rate. This shows that the best flow-rate estimate at 50 days is not particularly sensitive to the uncertainty of 1 to 2 days in our assignment of a time for the beginning of the flow down the hole. It also suggests that after roughly 10 days transient changes in the bore-hole temperature are slow enough that the steady-state approximation used in our first estimate is appropriate.

Based on a subjective assessment of the misfit of our data to the theoretical profiles, and a consideration of the uncertainties in the many parameter values that enter into the calculation, we adopt a best estimate of the time-average flow rate at $90 \pm 5 \mathrm{~m} / \mathrm{hr}\left(\approx 25 \times 10^{-3}\right.$ $\mathrm{m} / \mathrm{s}$ ). This is equivalent to a volume flux of $6360 \mathrm{l} / \mathrm{hr}$. The Reynolds number for this flow is given by:

$$
\operatorname{Re}=\frac{2 \mathrm{av}}{\nu} \simeq 4500-5000
$$

where $\nu$ is kinematic viscosity.

Because the critical Reynolds number for flow in a pipe is about 2300 (e.g., Vennard and Street, 1976, p. 383 ), this flow is transitionally turbulent. This probably justifies our assumption of radial uniformity of the bore-hole temperature.

\section{DISCUSSION}

In the foregoing, we treated the flow rate as constant with time. This is not strictly realistic, because the pressure differentials which drive the flow must be quenched to some degree by the mass flux. However, the similarity of all our temperature profiles suggests that the 

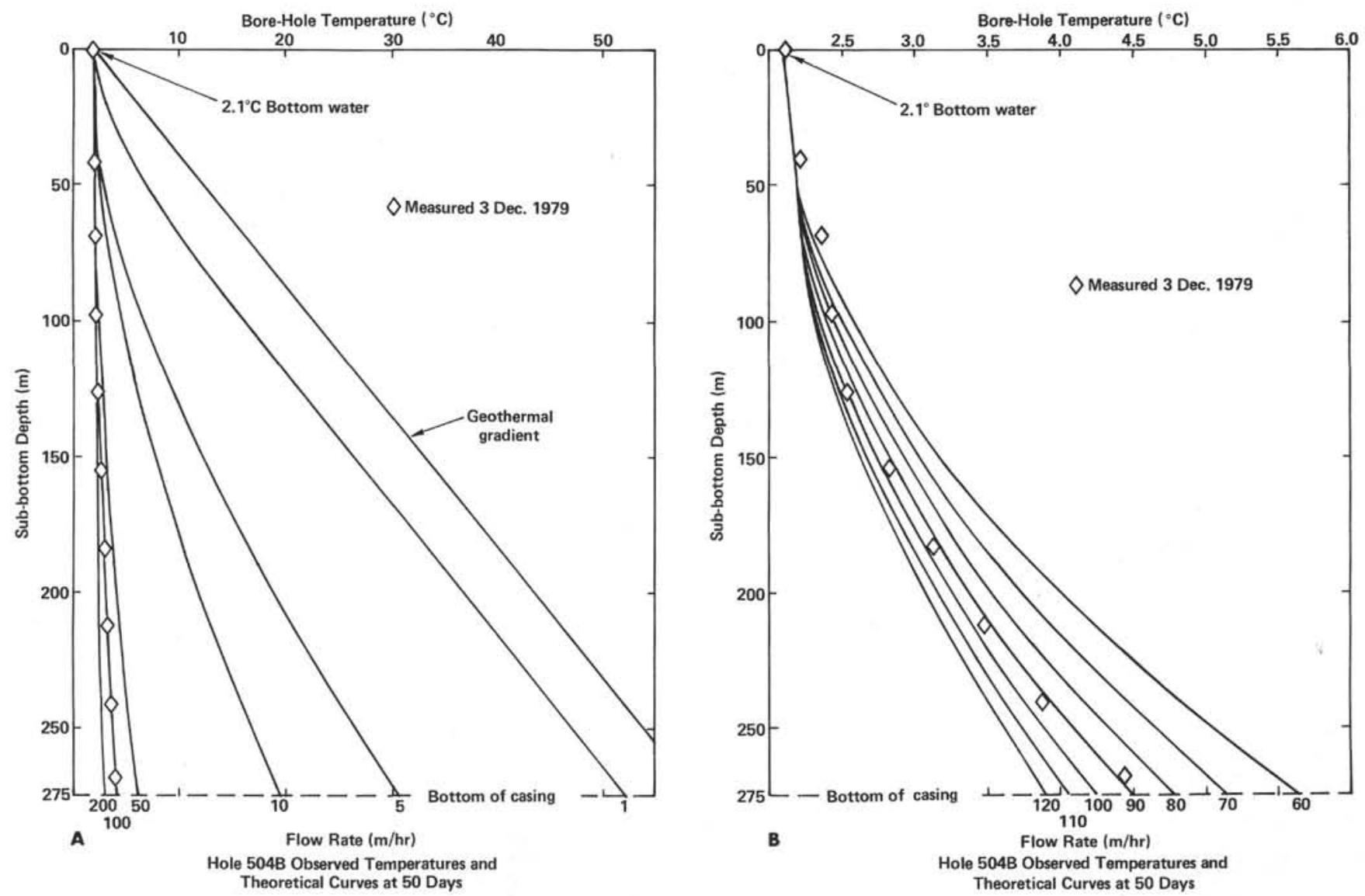

Figure 4. Near-equilibrium temperatures plotted on theoretical profiles for various down-hole flow rates.

dimunition of the pressure differential has been minor, so that a constant-flow-rate assumption is reasonably well justified.

It is difficult to obtain better than an order-of-magnitude estimate for the early flow rate from the Leg 69 logs, not only because of the problem in separating the drilling-temperature transient from the down-hole-flow transient, but also because the down-hole flow started sometime in the middle of a complex 10-day period of intermittent drilling, so that it is quite speculative to assign a time origin for the down-hole flow with respect to bore-hole temperatures corrected for the drilling disturbance. Moreover, existing correction procedures for the drilling transient are based on purely conductive equilibration of the hole, and do not include powerful advective heat transfer by fluid flow in the hole after drilling is stopped.

Nevertheless, to check that Leg 69 temperatures are consistent with flow rates determined from Leg $70 \mathrm{logs}$, we applied a simple conductive extrapolation (eq. (1); Bullard, 1947) to the Leg 69 data, which showed a significant temperature increase with time after drilling was stopped. In Figure 6, these results are overlaid on the transient development of temperature with a $90-\mathrm{m} /$ hr flow. Approximately 5 days elapsed between the time drilling was started and penetration of the formation at 350 meters sub-bottom (see below). An additional 5 days elapsed between penetration of this zone and ces- sation of Leg 69 drilling. The Leg 69 extrapolation is reasonably consistent with predicted temperatures for $90-\mathrm{m} / \mathrm{hr}$ flow at about 5 days, and suggests that no major change in flow rate occurred between Leg 69 and Leg 70 measurements.

The destination of the mass flux down 504B can be pinpointed with some accuracy by careful examination of the 3 December measured temperatures deeper than the casing. Figure 7 shows the entire temperature log, along with the theoretical curve for flow down the hole at $90 \mathrm{~m} / \mathrm{hr}$. It is remarkable that the two temperature points immediately beneath the casing lie directly on the theoretical curve, implying that no significant fluid injection occurs in the uppermost 50 meters of basalt. The zone of rapid temperature increase from about 360 to 400 meters can occur only if the vertical flow has virtually stopped (see Nowak, 1953); thus, nearly all the mass flow must be diverted into the basement between about 330 and 360 meters sub-bottom.

By Darcy's Law, the thinness of the radial injection zone (about $30 \mathrm{~m}$ ) must be due to some combination of local permeability contrasts and/or locally maintained pressure gradients. The latter possibility is convincingly ruled out by the in situ packer tests of Zoback and Anderson (this volume), who found formation fluid underpressures of about 6 to 12 bars in the basement to 489 meters sub-bottom. The maintenance of high local pressure gradients within the basement would require 


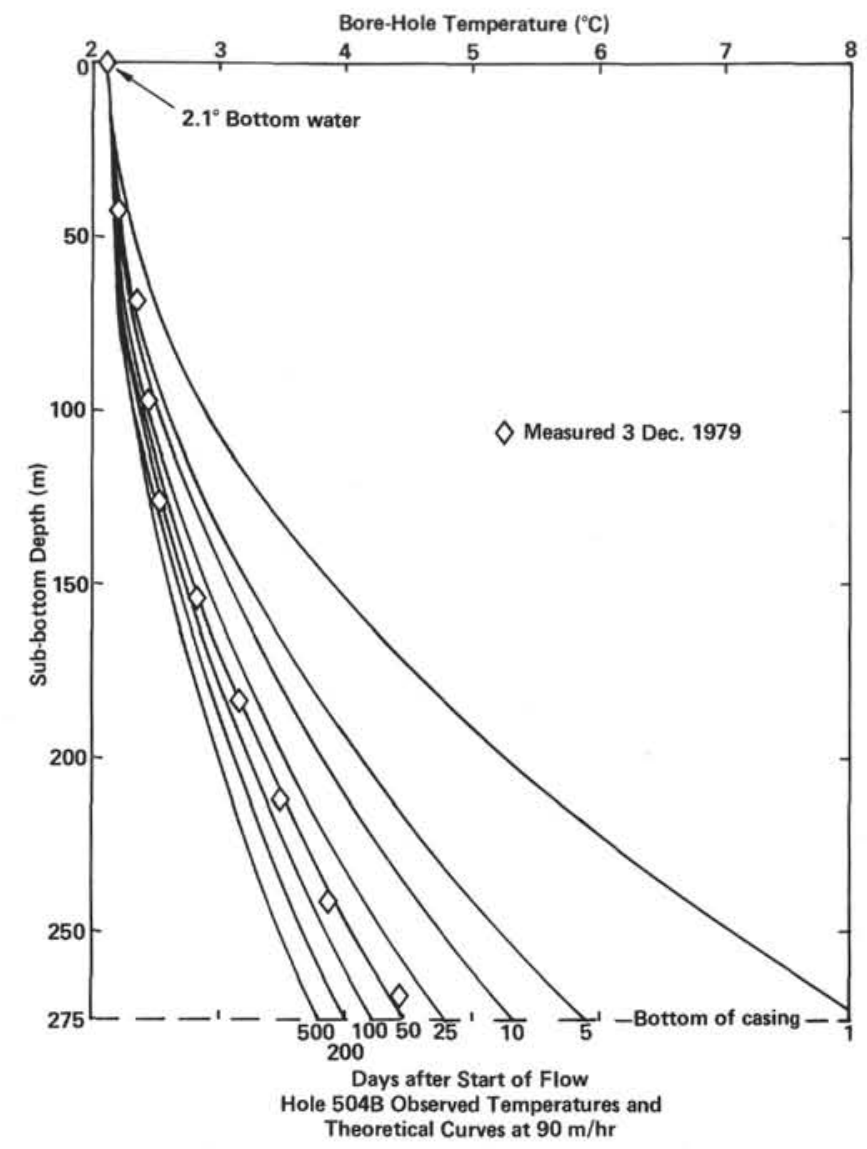

Figure 5. Near-equilibrium temperatures plotted on theoretical transient temperatures for $90 \mathrm{~m} / \mathrm{hr}$ down-hole flow rate.

unnaturally effective pressure seals. In contrast, the 275meter sediment cover is a much more effective barrier to flow and allows maintenance of a large pressure difference. Judging primarily from the uniformity of measured basement under-pressures, we must assume that the mass flux down Hole 504B debouches into an anomalously permeable formation. Under this assumption, we introduce a hydrological model in the next section that allows us to estimate the permeability of this formation, as well as predict the future mass flux down the hole.

\section{FLOW OF WATER THROUGH A BORE HOLE THAT PENETRATES UNDER- PRESSURED BASEMENT}

Judging from the temperature data and packer tests in Hole 504B, we assume that a high-permeability formation controls the flow, and that the initial pore pressure of this formation is less than hydrostatic. When the bore hole penetrates into the section, the water in the hole immediately is set at hydrostatic pressure, which remains constant because the hole is well connected to ocean bottom water.

We assume that the high-permeability formation is flat-lying, with a uniform thickness $h$ and infinite radial extent (Fig. 3). Formation hydraulic properties are

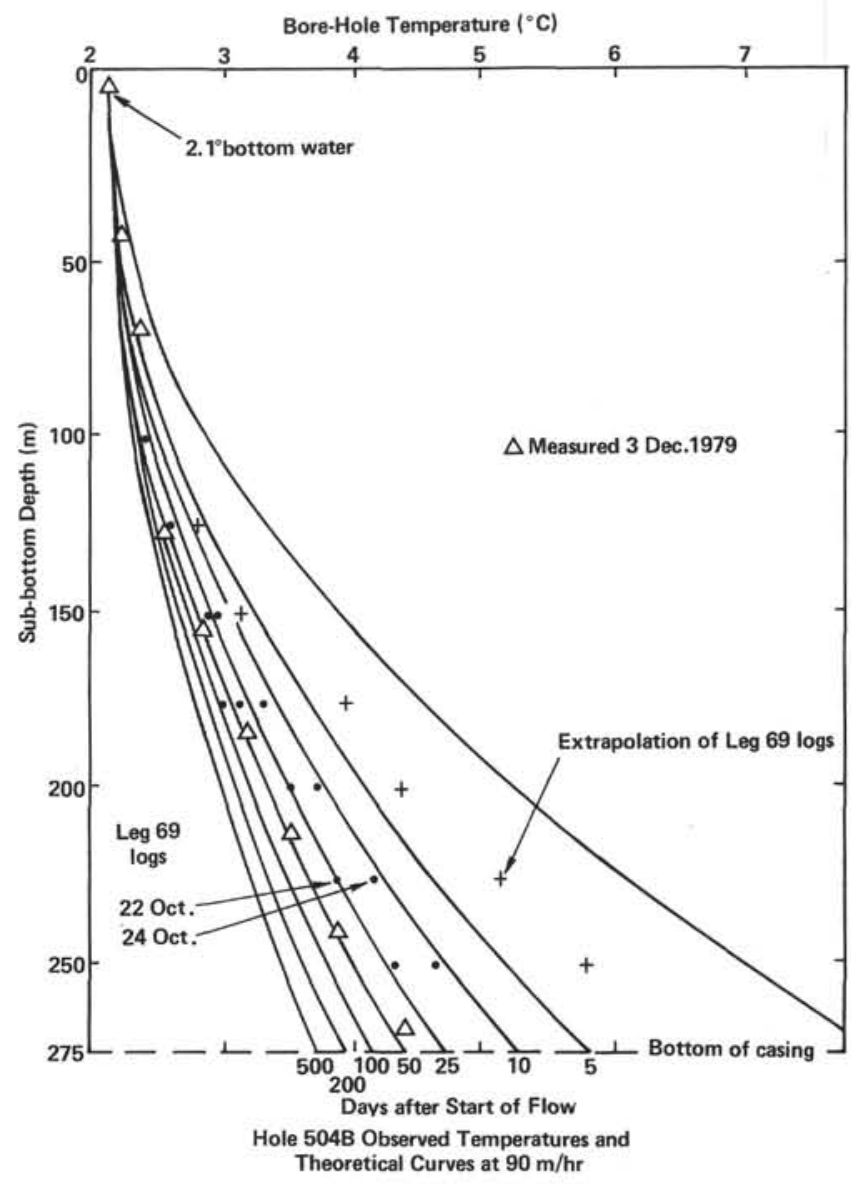

Figure 6. Leg 69 logs and extrapolated equilibrium temperatures on theoretical transient curves for $90-\mathrm{m} / \mathrm{hr}$ flow rate.

taken to be isotropic and constant: permeability $k$, porosity $\phi$, interstitial fluid viscosity $\mu$, and compressibility $C$. In an infinite radial geometry about a bore hole of radius $a$, the pressure $P(r, t)$ in this formation obeys the diffusion equation (Matthews and Russell, 1967):

$$
\frac{\partial^{2} p}{\partial r^{2}}+\frac{1}{r} \frac{\partial p}{\partial r}=\frac{\phi \mu C}{k} \frac{\partial p}{\partial t}
$$

with the initial condition $p(r, 0)=P_{\mathrm{i}}$ in situ pore pressure and the boundary condition $\mathrm{p}(\mathrm{a}, \mathrm{t})=P_{0}$ hydrostatic pressure.

This equation is completely analogous to the heatconduction problem in which an internal cylinder is held at a constant temperature, different by $\Delta T$ from the initial temperature, the solution of which we used above in the first flow-rate estimate (see eq. 2 and Table 2). Using this solution (Jaeger 1942, 1965; also Carslaw and Jaeger, 1959, p. 335), the pressure is given by:

$$
p(r, t)=\Delta P+\frac{2 \Delta P}{\pi} \int_{0}^{\infty} \mathrm{e}^{-x u^{2}} \frac{J_{0}\left(\frac{u r}{a}\right) Y_{0}(u)-Y_{0}\left(\frac{u r}{a}\right) J_{0}(u)}{J_{0}^{2}(u)+Y_{0}^{2}(u)} \frac{\mathrm{d} u}{u}(9)
$$

where $\Delta P \equiv P_{0}-P_{i}, x \equiv k t / \phi \mu C a^{2}, u$ is dimensionless. 


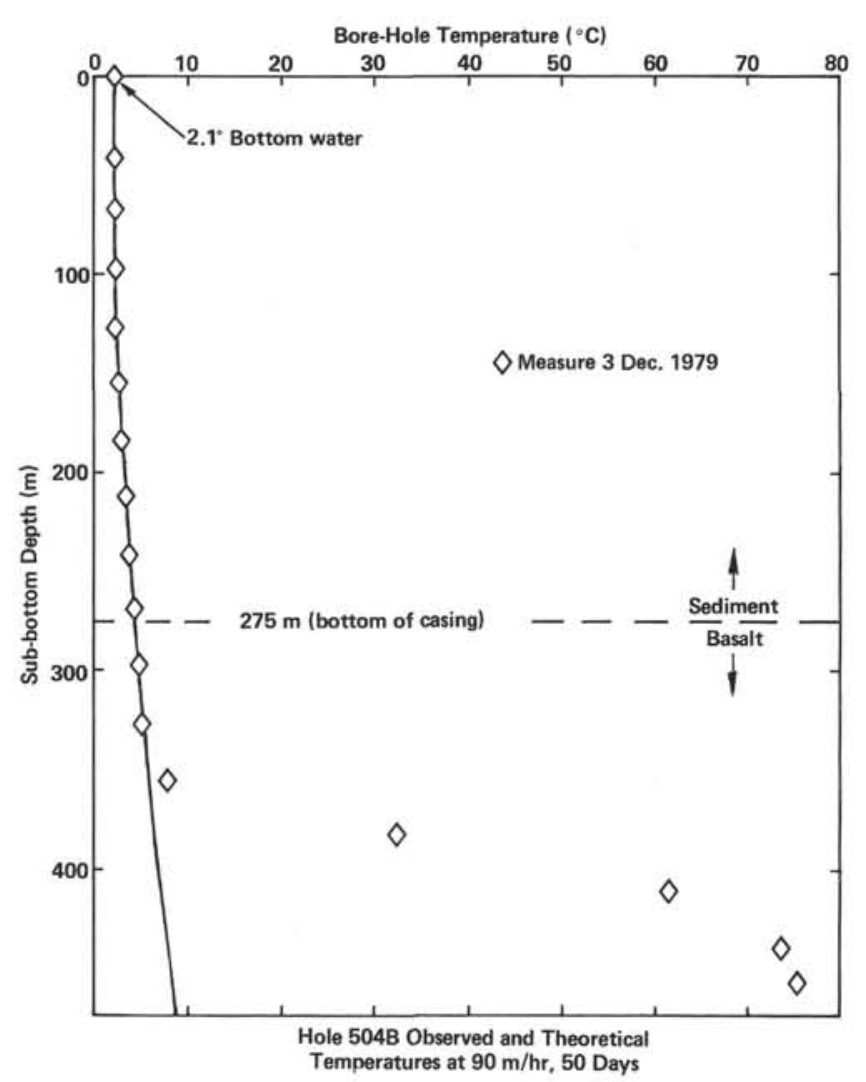

Figure 7. Equilibrium temperatures and theoretical curve extending below cased section of hole. Down-hole mass flux appears to be directed into basement between about 330 and 360 meters.

The flow of water $q$ through the cylindrical face of the bore hole, per unit area, is controlled by Darcy's Law:

$$
\begin{aligned}
\left.q\right|_{r=a} & =-\left.\frac{k \partial p}{\mu \partial p}\right|_{r=a} \\
& =\frac{4 k \Delta P}{\pi^{2} a \mu} \int_{0}^{\infty} \frac{\mathrm{e}^{-x u^{2} \mathrm{~d} u}}{u\left[J_{0}^{2}(u)+\mathrm{Y}_{0}^{2}(u)\right]} \equiv \frac{4 k \Delta P}{\pi^{2} a \mu} I(x)
\end{aligned}
$$

The total flow down the bore hole $q$, which is the quantity measured, is equal to the total flow through the face, that is,

$$
Q=2 a h q=\frac{8 \Delta P k}{\mu \pi^{2}} I(x)
$$

Jaeger and Clarke (1942) have tabulated this integral for $x=0.01$ to 1000 . Values also can be calculated readily by numerical integration. For large $x$ (i.e., greater than 1000 ), equation (1) can be approximated accurately by:

$$
\Delta P=\frac{4 \pi k h}{\mu}\left\{\frac{1}{\ln (4 x)-2 \gamma}-\frac{\gamma}{[\ln (4 x)-2 \gamma]^{2}} \cdots\right\}
$$

where $\gamma=0.572$.
These relations have been used to produce a plot of the flow down the hole in meters per hour per bar of pressure differential $\Delta P$ per meter of length of hole wall as a function of time after the well bore is pressurized (Fig. 8). Curves for four different permeabilities are shown. The permeability strongly controls the rate of flow, as clearly seen from equation 1 . It is clear that, for an infinite-reservoir model, the flow rate decreases very slowly with time.

The flow rates deduced from well temperature logs at Hole 504B, 10 and 50 days after the formation was exposed to hydrostatic pressure, are plotted on the curves. To place these points, we have assumed that the pressure difference $\left(P_{0}-P_{i}\right)$ is 6 to 12 bars and the flow rate is $90 \pm 5 \mathrm{~m} / \mathrm{hr}$. With this pressure difference, a high permeability of about 0.2 darcy $\left(2 \times 10^{-9} \mathrm{~cm}^{2}\right)$ is required to sustain the flow. Using different data, Zoback and Anderson calculated a bulk permeability of 0.040 darcies over the interval 320 to 490 meters sub-bottom in Hole 504B, which included the highly permeable 30 -meter section discussed above. Had they assumed that most of the flow occurred over the 30-meter section, they would have deduced a result in agreement with ours.

The model explains why the flow apparently changed so little in the 40 days between the Leg 69 and 70 measurements. The model also predicts that the flow will

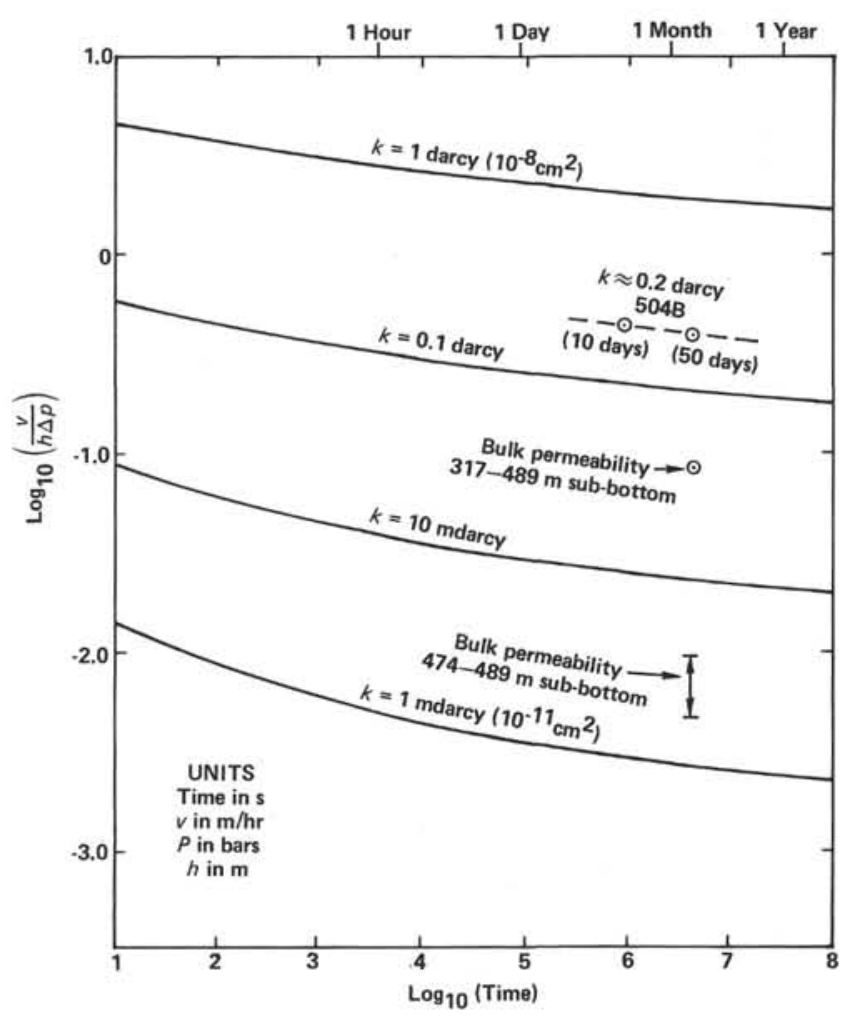

Figure 8. Log-log plot of down-hole flow rate normalized by pressure differential and height of injection zone, versus time, for infinitereservoir model. Theoretical curves given for four values of formation permeabilities. Two Hole 504B data points fix permeability of formation at 330 to 360 meters sub-bottom at about 0.2 darcy $\left(2 \times 10^{-13} \mathrm{~m}^{2}\right)$. The two bulk permeability values come from Zuback and Anderson (this volume). 
continue undiminished far into the future. For example, it predicts that the flow rate 3 years after Hole 504B was drilled will be on the order of $80 \mathrm{~m} / \mathrm{hr}$. Perhaps we will have a change to test this upon possible future re-entry of 504B.

At the same time, re-entry measurements will allow assessment of the suitability of an infinite-reservoir model, which must in reality fail at some finite length scale. A lower bound on the size of the real finite reservoir can be approximated by integrating a steady-state, radial Darcy Law (e.g., Dake, 1978, p. 116):

$$
Q_{r}=\frac{2 \pi r k h}{\mu} \frac{\mathrm{d} p}{\mathrm{~d} r}
$$

with $Q_{r}=$ total radial volume flux.

This integrates to

$$
p(r)-p(a)=\frac{Q_{r} \mu}{2 \pi k h} \ln \left(\frac{r}{a}\right)
$$

For our volume flux of $6.36 \mathrm{~m}^{3} / \mathrm{hr}$ into a 30 -meter-thick formation of $0.2 \mathrm{~m}$ darcy permeability, equation (14) yields a characteristic radial length scale of about 1.1 $\mathrm{km}$. This is really the approximate distance scale over which the hydrostatic pressure in the hole decays to the ambient formation under-pressure, and is not a direct measure of reservoir size; however, it does supply a minimum bound on the reservoir extent, because the mass flux into a smaller reservoir would be characterized by a recognizable temporal decrease of downhole flow rate.

\section{DOES WATER FLOW DOWN THE HOLE DEEPER THAN THE HIGH-PERMEABILITY FORMATION?}

At first glance, it seems clear that bottom water flowing down through the casing exits into the basement over a relatively thin section of the hole, 60 to 90 meters below the sediment/basement interface; however, some downward flow could exist in the bottom section of the hole as long as it is so slow that it has virtually no effect on the temperature gradient. Figure 4A shows that, for a flow of $1 \mathrm{~m} / \mathrm{hr}$, the gradient is little affected below 100 meters. The simple differential heat-exchanger model used earlier, in the first approximation of the down-hole flow rate, can be used to estimate the maximum rate undetectable with temperature measurements (see eq. 5).

This model gives, for the gradient in the bore hole, at a depth $z$ :

$$
\frac{\mathrm{d} T(z, a)}{\mathrm{d} z}=g\left[1-\mathrm{e}^{-\gamma z}\right]
$$

Using the parameters appropriate to Hole 504B (Table 2 ), this relation implies that flows less than about 1 to 2 $\mathrm{m} / \mathrm{hr}$ are not detectable in terms of a resolvable reduction in gradient in the bore hole. Therefore, there could be flow down Hole 504B of 1 to $2 \mathrm{~m} / \mathrm{hr}$, below $360 \mathrm{me}-$ ters sub-bottom, which is not detected. Assuming uniform basement under-pressure, the maximum undetect- able flow rate sets an approximate upper limit for the bulk permeability of the basement below 360 meters. Using our radially infinite reservoir model, this limit is strongly dependent on the vertical averaging interval $h$. For the Leg 69 drilled section to 490 meters, we find a maximum bulk permeability of about $10^{-3}$ darcy $\left(10^{-15}\right.$ $\mathrm{m}^{2}$ ) below the high-permeability zone. This limit is shown on Figure 8, and is in fair agreement with the Leg 69 bottom-hole value of 2 to $4 \times 10^{-3}$ darcy reported by Zoback and Anderson (this volume). For the entire basement below 360 meters, to 836 meters, this calculation yields a maximum bulk permeability nearly an order of magnitude less, about $10^{-4}$ darcy $\left(10^{-16} \mathrm{~m}^{2}\right)$.

\section{SUMMARY AND CONCLUSIONS}

From our suite of temperature measurements at Hole 504B, we directly conclude:

1) Before drilling, heat transfer in the upper 840 meters of oceanic crust at Hole 504B occurred by dominantly conductive means. The magnitude of the heat flow, about $190 \mathrm{~mW} / \mathrm{m}^{2}$, fits well with simple plate-tectonic predictions.

2) After penetration to basement, bottom water was drawn down the hole at $90 \mathrm{~m} / \mathrm{hr}$, into a 25 - to 30 -meter thick formation about 350 meters sub-bottom. This draw-down rate persisted for 50 days, indicating an under-pressured reservoir of $>1-\mathrm{km}$ radial extent.

3) The packer tests of Zoback and Anderson (this volume) indicated that basement pore waters were under-pressured by 6 to 12 bars (0.6-1.2 MPa). In combination with this result, the large volume flux into the aquifer yields an estimate for the formation permeability of about 0.2 darcy $\left(2 \times 10^{-13} \mathrm{~m}^{2}\right)$.

Hole 504B clearly penetrated a high-permeability conduit, of the type hypothesized to control water flow in the basement. The permeability estimate for this zone is about five times higher than the bulk basement permeability determined by Zoback and Anderson (this volume). High volume fluxes through such channels can result in high effective basement permeabilities on a scale of kilometers. The down-hole data show no evidence of flow in this conduit prior to drilling. In combination with the conductive sediment-temperature profile (Langseth et al., this volume), and the pervasive basement under-pressure to 489 meters sub-bottom (Zoback and Anderson, this volume), this strongly confirms the capacity of the 275 -meter sediment cover to seal the basement aquifer from the ocean bottom water.

The thermal data do not require active hydrothermal circulation in the upper kilometers of crust at Hole 504B, prior to the penetration of the sediment seal. On the contrary, the magnitude of the conductive heat flow and the uniform thermal gradients in both the sediment and the lowermost 400 meters of drilled basement argue against vigorous vertical hydrothermal convection at the site; however, the data do not preclude such circulation at very slow rates. The good agreement of conductive heat flows in the sediment and deep basement, which bracket the permeable aquifer, argues against lateral flows through it, unless the circulating water is completely equilibrated with the geothermal gradient. Such 
a situation could occur at very low lateral flow rates, or if the flow covered very large distances.

From the linearity of the deep basement thermal gradient, we infer that the basement under-pressures measured on Leg 69 to 490 meters sub-bottom (Zoback and Anderson, this volume) can be extrapolated to the full 836 meters Leg 70 hole depth. With basement permeabilities of $10^{-4}$ darcy $\left(10^{-16} \mathrm{~m}^{2}\right)$ and higher, vertical gradients of pressure cannot be sustained over periods of hundreds to thousands of years without invoking large vertical flows of pore waters. The uniform thermal gradient in the deep basement mitigates against such flow, and therefore against vertical pressure differences in the basement.

The origin of the basement under-pressure remains enigmatic. Using sediment-porosity data from Wilkens et al., (this volume), and estimates of sediment compressibility and permeability from Hamilton (1974) and Bryant et al., (1974), the time constant $L^{2} \phi \mu C / k$ for "pressure diffusion"' through the 275 -meter ( $\equiv L$ ) sediment layer is on the order of 1 to 1000 years; therefore, relict under-pressures cannot be maintained in the basement over longer periods of time, so an ongoing dewatering process is probably responsible. Tectonic processes with time scales much longer than 1000 years, in particular the subsidence of the cooling plate, probably could not maintain basement underpressure against the faster pressure diffusion through the sediments. Zoback and Anderson (this volume) present a model that demonstrates the feasibility of a cellular hydrothermal system, confined to basement, which explains both the basement under-pressure and a possible $\pm 25-\mathrm{mW} / \mathrm{m}^{2}$ amplitude variation in the surface heat flow.

Similar down-hole draw-down into basement after drilling has occurred at three other DSDP holes-335 and 396B on the Mid-Atlantic Ridge (Hyndman et al., 1976, 1977; Erickson and Hyndman, 1977), and 454A in the Mariana Trough (Uyeda and Horai, 1982). All these sites are located in sediment ponds on young crust, a hydrogeologic setting in which there exist large variations of hydraulic resistance to circulation between basement and bottom water. Large-scale hydrothermal convection from beneath the sediments toward discharge sites at basement highs and outcrops easily could reduce the volume and pressure of basement pore fluids, particularly if the sediment were effectively impermeable to recharge of bottom water. Such a large-scale system should be detectable by detailed multi-penetration heatflow surveys; in the case of Hole 504B, the surface-heatflow data are indefinite in this regard (compare Langseth et al., this volume; and Zoback and Anderson, this volume). A follow-up heat-flow survey addressed to this matter will be conducted in 1982 .

\section{NOTE ADDED IN PROOF}

Preliminary interpretation (by K.B.) of Leg 83 temperature measurements on re-entry of Hole 504B confirm the conclusions of this report with one possible exception. Nearly two years after the Leg 70 measurements, temperatures were still strongly depressed in the upper part of the hole, but the level at which the temperature recovered toward the geothermal gradient appeared to be about 20 meters shallow- er than on Leg 70 . This suggests that our narrow $(30 \mathrm{~m})$, high permeability aquifer model may be in error and that instead the entire upper 90 meters of basement may be an aquifer. If that is the case, the bulk permeability of this aquifer, as determined from the model of equations (8)-(12), would be 0.08 darcy, considerably less than the 0.2 darcy permeability obtained for the 30 -meter model. Nevertheless, 0.08 darcy is about twice the bulk permeability of the upper 214 meters of basement determined by Zoback and Anderson (this volume).

The Leg 83 measurements are discussed briefly in R. N. Anderson, J. Honnorez, et al. (1982). Leg 83 temperatures also indicate that the downhole flow had slowed considerably in the two years since Leg 70 . Toward a more complete interpretation of the Legs 69,70 , and 83 results, we anticipate an expansion of the mathematics used in this study to account for both a time-varying downhole flow and a finite radial reservoir size. Rather than rush to modify the conclusions of this chapter based on Leg 83 temperatures, we will wait until a complete study can be done and publish the results in Volume 83 .

\section{ACKNOWLEDGMENTS}

We thank the several DSDP and GO engineers who greatly contributed to the success of our temperature measurements. R. Parker and L. Dorman incisively advised the first author on the mathematical treatment. R. Hyndman and A. Lachenbruch provided encouraging reviews of the manuscript. The flexible plotting package of R. Parker and L. Shure allowed effortless plotting of our results. We thank Lola Boyce for cheerfully typing several revisions of the manuscript, and Jo Griffith for drafting the figures.

\section{REFERENCE}

Anderson, R. N., Honnorez, J., et al., 1982. Breaking the 600-metre barrier. Nature, 295:549-550.

Bryant, W. R., Deflache, A. P., and Trabant, P. K., 1974. Consolidation of marine clays and carbonates. In Inderbitzen, A. L. (Ed.), Deep-Sea Sediments Physical and Mechanical Properties: New York (Plenum), pp. 209-244.

Bullard, E. C., 1947. The time necessary for a borehole to attain temperature equilibrium. Monthly Notices Royal Astron. Soc., Geophys. Suppl., 5:127-130.

1954. The flow of heat through the floor of the Atlantic Ocean. Proc. Royal. Soc. London, Ser. A, 222:408-429.

Burch, T. K., and Langseth, M. G., in press. Heat flow determination in three DSDP boreholes near the Japan Trench. J. Geophys. Res.

Carslaw, H. S., and Jaeger, J. C., 1959. Conduction of Heat in Solids (2nd Ed.): Oxford (Clarendon Press).

Cooper, L. R., and Jones, C., 1959. The determination of virgin strata temperatures from observations in deep survey boreholes. Geophys. J. Royal Astron. Soc., 2:116-131.

Dake, E. P., 1978. Fundamentals of reservoir engineering: Amsterdam (Elsevier).

Erickson, A. J., and Hyndman, R. D., 1978. Downhole temperature measurements and thermal conductivities of samples, Site 396, Deep Sea Drilling Project Leg 46. In Dmitriev, L., Heirtzler, J., et al., Init. Repts. DSDP, 46: Washington (U.S. Govt. Printing Office), $389-400$.

Erickson, A. J., Von Herzen, R. P., Sclater, J. G., Girdler, R. W., Marshall, B. V., and Hyndman, R., 1975. Geothermal measurements in deep-sea drill holes. J. Geophys. Res., 80:2515-2528.

Hamilton, E. H., 1974. Prediction of deep-sea sediment properties: state-of-the-art. In Inderbitzen, A. L. (Ed.), Deep-Sea Sediments Physical and Mechanical Properties: New York (Plenum), pp. $1-43$.

Hyndman, R. D., and Drury, M. J., 1976. The physical properties of oceanic basement rocks from deep drilling on the Mid-Atlantic Ridge. J. Geophys. Res., 81:4042-4052.

Hyndman, R. D., Von Herzen, R. P., Erickson, A. J., and Jolivet, J., 1976. Heat-flow measurements in deep crustal holes on the MidAtlantic Ridge. J. Geophys. Res., 81:4053-4060.

1977. Heat flow measurements, DSDP Leg 37. In Aumento, F., Melson, W. G., et al., Init. Repts. DSDP, 37: Washington (U.S. Govt. Printing Office), 347-362.

Jaeger, J. C., 1942. Heat flow in the region bounded internally by a circular cylinder. Royal Soc. Edinburgh Proc., A, 61:223-228.

1956a. Numerical values for the temperature in radial heat flow. J. Math. Phys., 34:316. 
1956b. Conduction of heat in an infinite region bounded internally by a circular cylinder of a perfect conductor. Aust. J. Physics, 9:167-179.

, 1961. The effect of the drilling fluid on temperatures measured in boreholes. J. Geophys. Res., 66:563-569.

1965. Application of the theory of heat conduction to geothermal measurements. In Lee, W. H. K. (Ed.), Terrestrial Heat Flow: Washington (Am. Geophys. Union), pp. 7-23.

Jaeger, J. C., and Clarke, M, 1942. A short table of $\mathrm{I}\left(\mathrm{O}_{1} 1 ; \mathrm{x}\right)$. Royal Soc. Edinburgh Proc., A, 61:229-230.

Lachenbruch, A. H., and Brewer, M. C., 1959. Dissipation of the temperature effect of drilling a well in Arctic Alaska. U. S. Geol. Surv. Bull., 1083-C.

Lesem, L. B., Greytok, F., Marotta, F., and McKetta, J. J., Jr., 1957. A method of calculating the distribution of temperature in flowing gas wells. Petrol. Trans. AIME, 210:169-176.

Matthews, C. S., and Russell, D. G., 1967. Pressure build-up and flow tests in wells. Soc. Petrol. Eng. Monogr., 1.

Nowak, T. J., 1953. The estimation of water injection profiles from temperature surveys. Petrol. Trans. AIME, 198:203-212.

Uyeda, S., and Horai, K., 1982. Heat flow measurements on Deep Sea Drilling Project, Leg 60. In Hussong, D., Uyeda, S., et al., Init. Repts. DSDP, 60: Washington (U.S. Govt. Printing Office), 789-800.

Vennard, J. K., and Street, R. L., 1976. Elementary Fluid Mechanics (5th Ed.): New York (Wiley).

Von Herzen, R., and Maxwell, A. E., 1959. The measurement of thermal conductivity of deep-sea sediments by a needle-probe method. J. Geophys. Res., 64:1557-1563.

Yokota, T., Kinoshita, H., and Uyeda, S., 1980. New DSDP (Deep Sea Drilling Project) downhole temperature probe utilizing IC RAM (memory) elements. Bull. Earthquake Res. Inst. Tokyo, 54:441-462.

\section{APPENDIX}

Solution of Transient Temperature Field for Bore-Hole Flow (after Lesem et al., 1957)

For a semi-infinite geometry of the cased section of the hole, with the depth coordinate $z$ positive downward, the following equations hold:

In the earth, $r>a$, neglecting the vertical-heat-conduction term; the earth temperature $T_{\mathrm{e}}(r, z, t)$ fulfills:

$$
\frac{\partial^{2} T_{\mathrm{e}}}{\partial r^{2}}+\frac{1 \partial T_{\mathrm{e}}}{r \partial r}=\frac{1}{x} \frac{\partial T_{\mathrm{e}}}{\partial t}
$$

with the boundary conditions:

$$
\begin{gathered}
T_{\mathrm{e}}=0 \text { at } z=0 \text {, all } t \\
T_{\mathrm{e}} \rightarrow g z \text { as } r \rightarrow \infty
\end{gathered}
$$

and the initial condition

$$
T_{\mathrm{e}}=g z \text { at } t=0 \text {, all } z
$$

Assuming radial mixing in the borehole, so there is no radial variation of bore-hole water temperature $T_{\mathrm{w}}(z, t)$, thermal balance in the bore hole is expressed by

$$
\pi a^{2}(\varrho c)_{\mathrm{w}}\left(\frac{\partial T_{\mathrm{w}}}{\partial T}+v \frac{\partial T_{\mathrm{w}}}{\partial z}\right)=\left.2 \pi a K_{\mathrm{e}} \frac{\partial T_{\mathrm{e}}}{\partial r}\right|_{r=a}
$$

or

$$
\begin{gathered}
\frac{\partial T_{\mathrm{w}}}{\partial t}=\left.\beta \frac{\partial T_{\mathrm{e}}}{\partial r}\right|_{r=a}-v \frac{\partial T_{\mathrm{w}}}{\partial z} \\
\text { with } \beta \equiv 2 K_{\mathrm{e}} / a(\varrho c)_{\mathrm{w}}
\end{gathered}
$$

The water temperature obeys the boundary conditions:

$$
\begin{aligned}
& T_{\mathrm{w}}=0 \text { at } z=0, \text { all } t \\
& T_{\mathrm{w}}(a)=T_{\mathrm{c}}(a) \text { all } z, t
\end{aligned}
$$

and the initial condition

$$
T_{\mathrm{w}}=g z \quad \text { at } t=0
$$

The system of equations (A1) through (A9) is an initial-value problem in both time and depth, and can be solved by a double Laplace Transform. If $\hat{T}(s, z)$ denotes the Laplace Transform with respect to time, and $\vec{T}(s, p)$ denotes the iterated transform with respect to depth, the fully transformed equations reduce to

$$
\begin{aligned}
& \frac{\partial^{2} \bar{T}_{\mathrm{e}}}{\partial r^{2}}+\frac{1}{r} \frac{\partial \bar{T}_{\mathrm{e}}}{\partial r}=\frac{1}{x}\left[s \bar{T}_{\mathrm{e}}-\frac{g}{p^{2}}\right] \\
& (s+v p) \bar{T}_{\mathrm{w}}-\frac{g}{p^{2}}=\left.\beta \frac{\partial \bar{T}_{\mathrm{e}}}{\partial r}\right|_{r=a}
\end{aligned}
$$

with the boundary conditions

$$
\bar{T}_{\mathrm{w}}(a)=\bar{T}_{\mathrm{e}}(a)
$$

and

$$
\bar{T}_{\mathrm{e}} \rightarrow \frac{g}{s p^{2}} \quad r \rightarrow \infty
$$

The solution to (A10) satisfying (A13) is

$$
\tilde{T}_{\mathrm{e}}=\frac{g}{s p^{2}}+A K_{0}(q r), \text { with } q=\sqrt{s / x}
$$

and with $A$ determined using (A12) and (A11)

$$
A=-g v / s p\left[(s+v p) K_{0}(q a)+q K_{1}(q a)\right]
$$

This yields, for the transformed water temperature:

$$
\bar{T}_{\mathrm{w}}=\frac{g}{p^{2}}\left(\frac{s K_{0}(q a)+\beta q K_{1}(q a)}{s\left[(s+v p) K_{0}(q a)+\beta q K_{1}(q a)\right]}\right)
$$

This can be rearranged to isolate terms in $p$ :

$$
\frac{\bar{T}_{\mathrm{w}}}{g}=\frac{s K_{0}(q a)+\beta q K_{1}(q a)}{s v K_{0}(q a)}\left(\frac{1}{p^{2}}\right)\left(\frac{1}{p+\frac{s}{v}+\frac{\beta q K_{1}(q a)}{v K_{0}(q a)}}\right)
$$

which can be inverted with respect to $p$ using the convolution theorem:

$$
\begin{aligned}
\hat{T}_{\mathrm{w}}(s, z)-\frac{g z}{s} & =\frac{g v}{s^{2}\left(1+\left[\frac{\beta q K_{1}(q a)}{s K_{0}(q a)}\right]\right)} \\
& \cdot\left(\exp \left[\frac{-s z}{v}\left(1+\frac{\beta q K_{1}(q a)}{s K_{0}(q a)}\right)\right]-1\right)
\end{aligned}
$$

The non-exponential part on the right-hand side of (A18) arises in the solution of the radial-heat-conduction problem about cylinder with a constant supply of heat [Carslaw and Jaeger, 1959, p. 342, eq. (6)]. Thus, the exponential part may be interpreted as representing the variation of the effective source strength with depth, because of the flow down the hole.

(A18) must be inverted by contour integration about a branch point at $s=0$ (see Lesem et al., 1957, for details). The final solution for the water temperature is: 


$$
T_{\mathrm{w}}(t, z)=g z \frac{-4 g v a^{3} \beta}{\pi^{2} x} I_{1} \frac{+2 g v a^{2}}{\pi x} I_{2}
$$

with

$$
\begin{gathered}
I_{1}=\int_{0}^{\infty} \frac{\mathrm{d} u}{u^{3}} \frac{\left[1-\exp \left(\frac{-x t u^{2}}{a^{2}}\right)\right]}{\Delta u} \\
I_{2}=0 \text { if } t \leq z / v \\
=\int_{0}^{\infty} \frac{\mathrm{d} u}{u^{3} \Delta u}\left(1-\exp \left[\frac{-u^{2} x}{a^{2}}\left(t-\frac{z}{v}\right)\right]\right) \\
\Delta u=\exp \left(\frac{-u \beta z \mathrm{f}_{2}}{v a \mathrm{f}_{1}}\right) C(u) \text { if } t>z / v \\
u J_{0}(u)-\alpha J_{1}(u)^{2}+u Y_{0}(u)-\alpha Y_{1}(u)^{2}
\end{gathered}
$$

$$
\begin{gathered}
\mathrm{f}_{1}=J_{0}^{2}(u)+Y_{0}^{2}(u) \\
\mathrm{f}_{2}=J_{0}(u) J_{1}(u)+Y_{0}(u) Y_{1}(u) \\
C(u)=\left[u \alpha \mathrm{f}_{2}-u^{2} \mathrm{f}_{1}\right] \sin \left(\frac{2 \beta z}{\pi v a \mathrm{f}_{1}}\right)+\frac{2 \alpha}{\pi} \cos \left(\frac{2 \beta z}{\pi v a \mathrm{f}_{1}}\right) \\
\alpha=\frac{2(\varrho c)_{\mathrm{e}}}{(\varrho c)_{\mathrm{w}}}
\end{gathered}
$$

Despite the rather imposing appearance of (A21), both integrands are quite smooth and decay very rapidly as $u$ increases. Thus, they are amenable to numerical integration by any number of basic techniques. For this study, results were obtained by Gauss-Legendre quadrature over a finite interval. Convergence of the results was checked by first increasing the number of nodes used in each small subinterval, and then increasing the upper finite interval of the integration. Comparison to a later trial run with Romberg integration suggests a maximum error no worse than 1 part in 1000-certainly far better than the precision to which the material parameters in (A19) are known. 